\title{
A Educação Física no Ensino Médio e a Avaliação Emancipatória: um estudo de caso
}

Denise Grosso da Fonseca ${ }^{\mathrm{a}, *} \mathbb{D}^{\mathbb{D}}$, Vicente Molina Neto ${ }^{\mathrm{a}}{ }^{\mathbb{C}}$, Lisandra Oliveira e Silva ${ }^{\mathrm{B}}$

Palavras Chave:

Educação Física Escolar; Ensino Médio;

Avaliação;

Avaliação

emancipatória.

\section{RESUMO}

Neste artigo apresenta-se uma investigação cujo objetivo foi compreender o modo como os professores percebem e praticam a avaliação a partir da perspectiva emancipatória presente na Proposta Pedagógica para o Ensino Médio Politécnico e Educação Profissional, integrada ao Ensino Médio 2011-1014, no estado do Rio Grande do Sul. Trata-se de uma pesquisa de corte qualitativo, com ênfase em estudo de caso, em duas escolas estaduais, de uma cidade da fronteira oeste do Estado. A análise das informações permite declarar que: o contexto imprime suas marcas; há dúvidas e diferentes percepções sobre avaliação emancipatória; há tensionamentos no entendimento entre nota e conceito; e, a questão da prova suscita discussão sobre a diversificação de instrumentos avaliativos.

\begin{abstract}
This article presents an investigation whose objective was to understand the effects of the "Pedagogical Proposal for Polytechnic Secondary Education and Professional Education integrated to High School 2011-1014", in the pedagogical practice of tion teachers, in Rio Grande do Sul. Is based on a qualitative research, with emphasis on a case study, in two state schools of a city on the western border of the State. The analysis of the information allows to state that: the context prints your marks; there are doubts and different perceptions about emancipatory evaluation; There is tension in the understanding between note and concept; And, the issue of proof raises a discussion about the diversification of evaluation instruments.
\end{abstract}

\section{Keywords:}

Physical School

Education;

High School;

Evaluation;

Emancipatory

evaluotion.

Palavras Chave:

Educación Física

Escolar;

Escuela secundaria;

Evaluación;

Evaluación

emancipatoria.

\section{RESUMEN}

En este artículo se presenta una investigación cuyo objetivo fue comprender el modo como los profesores perciben y practican la evaluación a partir de la perspectiva emancipatoria presente en la Propuesta Pedagógica para la Enseñanza Media Politécnico y Educación Profesional integrada a la Enseñanza Media 2011-1014 en el estado de RS. Es una investigación de corte cualitativo, con énfasis en estudio de caso, en dos escuelas estatales de una ciudad de la frontera oeste del Estado. Las analises indicam que: el contexto imprime sus marcas; hay dudas y diferentes percepciones sobre evaluación emancipatoria; hay tensiones en el entendimiento entre nota y concepto; y la cuestión de la prueba suscita una discusión sobre la diversificación de instrumentos de evaluación.

\footnotetext{
a Universidade Federal do Rio Grande do Sul, Escola de Educação Física, Fisioterapia e Dança, Departamento de Educação Física, Porto Alegre, RS, Brasil.
}

\section{*Autor correspondente: \\ Denise Grosso da Fonseca \\ E-mail: dgf.ez@terra.com.br}

Recebido em 11 de julho de 2019; aceito em 11 de dezembro de 2019. 


\section{INTRODUÇÃO}

A implantação da Proposta Pedagógica para o Ensino Médio Politécnico e Educação Profissional Integrada ao Ensino Médio 2011-1014, no estado do Rio Grande do Sul - RS, instigou a realização da pesquisa "A Educação Física no Ensino Médio - EM: estudos de casos na Rede Estadual de Ensino do RS", procurando compreender seus efeitos na prática pedagógica dos professores de Educação Física-EF, através de uma pesquisa de natureza qualitativa, com ênfase em estudos de caso.

Em uma conjuntura em que as bases políticopedagógicas para o EM foram alteradas a partir da Lei 13.415/2017 e a aprovação da Base Nacional Comum Curricular (BNCC), comprometem a legitimidade da EF, bem como outros aspectos significativos que impactam esse nível de escolaridade, a Proposta Politécnica (20112014) protagonizada pelo Estado do RS, apresenta ao debate, elementos importantes para a reflexão sobre a avaliação do ensino e da aprendizagem da EF no EM.

O documento base da proposta do RS - 20112014, defende que a educação do século XXI coloque o EM como efetiva etapa final da Educação Básica, "contemplando a qualificação, a articulação com - mundo do trabalho e práticas produtivas, com responsabilidade e sustentabilidade e com qualidade cidadã. (RIO GRANDE DO SUL, 2011, 2014, p.4)". Para tanto, apoia-se nos princípios da Relação Parte - Totalidade; Reconhecimento de Saberes; Teoria Prática; Interdisciplinaridade, Avaliação Emancipatória e Pesquisa, que orientam as ações e práticas pedagógicas.

A vertente emancipatória, proposta no documento, está sustentada nas ideias de Saul (1998), que afirma que o paradigma da avaliação emancipatória se mostra adequado na avaliação de programas e políticas quando se tem uma perspectiva crítico-transformadora da realidade e se deseja, como processo avaliativo, uma prática democrática. Entendemos que a avaliação emancipatória está alinhada com a pedagogia crítica, no sentido de desvelar as relações de poder e de dominação que permeiam a sociedade e a escola e, nesse sentido, conjugar conhecimento e poder para o desenvolvimento de cidadãos críticos e ativos (MCLAREN, 1977).

Nessa perspectiva, Silva e Silveira (2018) buscaram compreender as formas como alunos e professores de EM percebiam suas vivências em relação às práticas de avaliação da EF no âmbito do Ensino Médio Politécnico, considerando a avaliação emancipatória. Os autores apontaram dificuldade por parte, principalmente, dos professores quanto ao aprofundamento e envolvimento em uma prática avaliativa emancipatória. Em relação aos discentes, indicaram não haver noção sobre o que seria a avaliação emancipatória. Assim, para os autores, se evidencia a fragilidade de conhecimentos sobre o tema, por parte dos atores do processo, sugerindo que a distância entre a teoria proposta e a prática se deve a inúmeros fatores, mas principalmente à falta de capacitação dos professores, bem como às precárias condições do sistema educacional.

Neste artigo nos propomos a apresentar os achados de um dos nossos casos estudados, cujo objetivo foi compreender o modo como os professores percebem e praticam a avaliação, a partir da perspectiva emancipatória, presente nas orientações curriculares da referida proposta.

\section{METODOLOGIA}

A pesquisa qualitativa de acordo com Negrine (2010), se baseia na descrição, na análise, na interpretação e na discussão das informações, procurando compreendêlas no âmbito de seus contextos. Nessa perspectiva, o estudo de caso segundo Molina (2010), não é em si uma escolha metodológica, e sim, a escolha de um objeto a estudar, podendo, entretanto, ser encarado como uma conjugação entre a escolha do objeto a ser estudado e a estratégica metodológica utilizada.

Diante da abrangência e da diversidade cultural presentes no sul do Brasil, o trabalho empírico foi organizado por regiões geopolíticas, tendo como campo de estudos escolas estaduais de EM. A obtenção de informações foi realizada através de observação, de entrevista semiestruturada e de diário de campo, e os colaboradores deste estudo, foram seis professores de Educação Física e duas Supervisoras Pedagógicas.

As informações obtidas foram descritas, analisadas e interpretadas procurando-se percebê-las, não apenas como dados objetivos, mas como processos carregados de significado, dos próprios sujeitos da pesquisa, de modo que possam ampliar as reflexões no seio da realidade na qual estão inseridos (BOGDAN; BIKLEN, 1994).

Neste artigo apresentamos o caso de Quaraí, cidade situada na fronteira oeste do estado do RS. O contexto, em que se situa o caso do estudo é olhado na perspectiva de Cyro Martins (1937; 1944; 1954), contracenando elementos que historicamente tem sido causa e efeito da marginalização do homem da campanha gaúcha, relacionando com a segregação do jovem contemporâneo e sua possível exclusão do E M.

\section{RESULTADOS E DISCUSSÃO}

Ao serem questionados sobre como percebiam a Avaliação, na perspectiva da nova orientação, os professores narraram aspectos do contexto geopolítico 
que constituem o cenário socioeconômico e que implicam na vida dos estudantes na escola; manifestaram diferentes entendimentos sobre a perspectiva avaliativa em implantação e declararam ter inúmeras dúvidas para encarar as mudanças que acompanhavam a referida proposta. A partir da interpretação de suas falas e das observações realizadas, emergiram quatro categorias de análise: - As marcas do contexto; - Olhares sobre a avaliação; - Conceito e nota: - O qualitativo e o quantitativo e - A questão da prova, as quais passaremos a apresentar em diálogo com os autores que nos referenciaram.

\section{As Marcas do Contexto}

A questão geopolítica, importante critério para o desenvolvimento dos estudos propostos, traz elementos que caracterizam as diferentes regiões do estado do RS. A cidade de Quaraí possui uma população de 24.987 habitantes, dista 590 quilômetros de Porto Alegre e tem sua economia baseada na tradição pecuarista, com forte investimento no comércio e, do mesmo modo, na agricultura através da produção de arroz.

A presença no grupo de pesquisa ${ }^{1}$ de uma professora natural daquela cidade nos ajuda a olhar para a educação quaraiense desde a década de 1960, vislumbrando que historicamente, a continuidade aos estudos com vistas ao ensino superior, é um privilégio reservado a uma parcela de jovens cujas famílias usufruem de condições econômicas favoráveis.

Tal fenômeno, conforme as informações da atual pesquisa, continua afetando a vida da população juvenil oriunda das classes populares do lugar. Nesse sentido, para além das questões que orientaram o objetivo central relacionado à avaliação, este estudo desvela aspectos contextuais que impactam a trajetória educacional dos jovens de Quaraí.

Manifestações de professores colaboradores desta pesquisa, reafirmam que, embora muitas oportunidades tenham surgido nos últimos anos, possibilitando alternativas para a continuidade na escolarização e ingresso no Ensino Superior fora dali, porque a cidade não possui esse nível educacional ${ }^{2}$, a realidade, em relação às condições concretas para concluir a educação básica, continua evidenciando grandes dificuldades. As

1 Grupo de Estudos Qualitativos Formação de Professores e Prática Pedagógica em Educação Física e Ciências do Esporte (F3P-EFICE), vinculado à ESEFID/UFRGS.

2 A Unipampa, Universidade Federal do Pampa, criada para ampliar a Educação Superior na metade sul do estado do RS, tem dez campi distribuídos nas cidades de São Borja, Itaqui, Uruguaiana, Alegrete, Santana do Livramento, São Gabriel, Caçapava do Sul, Dom Pedrito, Bagé e Jaguarão. Quaraífoi uma das únicas cidades da região que ficou fora do processo. http://porteiras.unipampa.edu.br/uruguaiana/ index. php?option=com_content $\&$ view=article $\& i d=45 \&$ Itemid $=54$. Consulta em 03/01/2017. condições socioeconômicas locais que não se alteraram significativamente nos últimos 50 anos e a necessidade de ingresso no restrito mercado de trabalho, promove altos níveis de desistências e de exclusões escolares, dadas as circunstâncias que reproduzem precariedades presentes em décadas passadas. Tais constatações nos instigam a questionar: quais fatores seriam determinantes dessa realidade que teima em acompanhar gerações de jovens marcadas pela ausência de condições materiais objetivas para concluir a educação básica e acessar ao ensino superior?

As diferenças evidenciadas no projeto de vida de cada um não são processos naturais relacionados unicamente ao interesse individual pelos estudos. Desde o início do século passado, as condições socioeconômicas e culturais de cada família, produzidas naquele contexto de cidade, da região da Campanha rio-grandense, marcada pela tradição pecuarista no início de sua urbanização, era acompanhada pelo surgimento de vilas na periferia, constituídas pela pobreza de seus moradores expulsos do campo e extraviados pelas cidades. Um tipo de marginalização muito próprio de uma época em que as mudanças que se operavam, a partir da reorganização dos modos de produção do campo, produziam o êxodo rural nas áreas de latifúndio e o dramático desemprego do homem oriundo do pampa. É o processo descrito por Cyro Martins ${ }^{3}$ nos romances Sem Rumo (1937), Porteira Fechada (1944) e Estrada Nova (1954), que compõem a Trilogia do Gaúcho a Pé, em que retrata a degradação do homem marginalizado pelos efeitos das transformações ocorridas na campanha gaúcha.

Privado das condições de vida que lhe modelaram o caráter, o gaúcho, não dispondo mais da fartura, do cavalo e da distância, decaiu como tipo representativo de um padrão de existência. Mas a culpa desse declínio não cabe somente à sua índole afeita ao espírito de aventura e de certo modo hostil à monotonia do trabalho duro e paciente, reclamado pelas novas circunstâncias do meio. Na verdade, as massas campeiras foram dispensadas - por que não dizer excluídas? - por desnecessárias, numa concorrência lógica do rumo que tomavam as lidas campeiras (MARTINS, 1997, p. 27).

Nesse sentido, a obra de Cyro Martins desvela as agruras do gaúcho abandonado à própria sorte, sem rumo, em meio à vida que se desenrola no mundo urbanizado. Mas o que tudo isso tem a ver com o estudo que estamos a desenvolver? De que forma a obra de Cyro Martins adquire ressonância nas reflexões que nos propomos a fazer? De que modo tais condicionantes repercutem,

3 Cyro Martins (1908-1995), médico psicanalista e escritor quaraiense, com extensa obra dedicada à psicanálise e à literatura. 
hoje, na marginalização ainda presente nessa cidade? Quem é o gaúcho sem rumo, hoje?

Diante de tantas possíveis relações, a figura desse sujeito perdido em um tempo distante, que já alterou seu cenário, pode bem ser o jovem, o quase "sem rumo", que hoje bem ou mal chega ao ensino secundário, e se encontra habitando as escolas públicas do RS. O que procuram, na escola, esses jovens, cujas juventudes circulam nas salas de aulas, pátios, ginásios, quadras e demais dependências das escolas? A falta de rumo pode ser relacionada ao próprio processo educativo em busca de seu caminho que nos instiga a indagar: de que modo as políticas públicas têm respondido às demandas do jovem contemporâneo, em especial daquele oriundo das classes populares, que frequenta a escola pública e parece não encontrar motivos para permanecer, ou, até mesmo, usufruir dos conhecimentos que ela Ihe disponibiliza? Como a prática avaliativa, desenvolvida nas escolas, pode contribuir com a educação dos jovens? De que modo a Educação Física se insere nesse processo?

Entendemos que para dar resposta a tão complexas questões, vinha sendo gestado um projeto educacional, ao encontro de uma educação de nível médio, comprometida com uma formação integral e cidadã. As Diretrizes Curriculares Nacionais para o Ensino Médio (DCNEM, 2012) apresentam como propósito superar a histórica fragmentação que acompanha a trajetória do EM, procurando a construção de novas perspectivas pedagógicas para enfrentar as dissonâncias que impedem a decolagem segura e efetiva dessa etapa da escolaridade básica. Nesse sentido, consubstanciamos essas ideias com a fala de uma das colaboradoras deste estudo que diz:

Eu acho que foi um grande avanço das DC porque se democratizou o acesso, essa universalização do $E M$, porém ainda tem o desafio que é a permanência do aluno [...] nessa faixa etária onde estão ingressando no mundo do trabalho até informal sem uma qualificação [...] e nosso grande desafio é contemplar os anseios dos jovens para que ele possa dar conta do seu estudo e formar um projeto bonito de vida, familiar, já que aqui em Quarai o que tem de trabalho é o comercio. Então eles vão para essa área sem muita qualificação e em seguida estão, novamente, procurando outras formas para contribuir com a família. Então acho que foi muito bom vir esse desenho curricular [...] (Professora EP)

Portanto, a proposta em análise, na visão da professora, apresenta perspectivas de democratização do acesso, mas, ainda, não contempla o problema da permanência do jovem na escola, em meio aos desafios conjunturais cotidianos.

\section{Olhares Sobre a Avaliação}

Diferentes olhares perpassam a prática avaliativa, problematizada a partir da proposta emancipatória. Parece haver diferentes entendimentos sobre tal concepção os quais se explicitam na manifestação dos docentes entrevistados.

Acredito que caiu o padrão da avaliação, ela deveria ser mais rígida. [..] O aluno tem muitas chances, [...] Porque a cobrança está cada vez menor, e os alunos perceberam isso. [...] Isso vem fazendo, de certa forma, que o empenho deles venha caindo (Professor EP).

Para esse professor a avaliação emancipatória está relacionada a certa facilitação nas exigências a serem estabelecidas aos estudantes, sugerindo que os alunos, em consequência, se despreocupam em estudar mais, evidenciando menor empenho nesse ato. É importante refletir sobre a percepção aqui explicitada. Parece haver uma compreensão sobre o significado da perspectiva emancipatória, diferente daquele discutido nos marcos referenciais. A dimensão que assume o protagonismo do aluno, através da tomada de consciência sobre seu papel no ato de aprender e, paralelamente, o papel do professor como mediador/problematizador nesse processo, não perpassam a ideia em discussão. A fala do professor indica uma visão de descomprometimento com a aprendizagem, por parte do estudante, em resposta ao suposto abrandamento da exigência do professor.

Tal aspecto sugere, ainda, a dificuldade de os professores compreenderem as alterações nas relações de poder entre professor e estudante frente ao processo avaliativo que nos leva a indagar: - como fazer a ruptura com o modelo avaliativo classificatório, quantitativo, cuja supremacia está sempre representada na ação do professor sobre o aluno, sem cair no (aparente) extremo oposto? Como estabelecer o processo de ensinoaprendizagem-avaliação sob uma perspectiva menos autoritária e mais dialógica, que convide o estudante a refletir sobre seu desempenho? A compreensão da avaliação como tomada de consciência, e, nesse sentido, emancipatória, um dos princípios estruturantes do projeto educativo do RS (2011-2014) parece ter se constituído em um dos processos desafiadores na caminhada de implantação da proposta. A fala de uma das professoras entrevistadas, de alguma forma, explicita o processo de busca e construção que se estabeleceu na escola:

A gente procurou a maneira de avaliar, de como organizar essa avaliação, mas não foi uma coisa segura no início. [...] até hoje a gente tá mudando, tentando adequar da melhor forma possível tudo (Professora MD). 
Outro colaborador demonstra sua compreensão quando diz:

Eu acredito que a avaliação emancipatória tenha como princípio um maior envolvimento dos alunos no processo [...]. Eu acredito nesse acompanhamento dia-a-dia, da avaliação contínua, não só de uma prova ou de um trabalho (Professor MD).

Essa manifestação vai ao encontro da ideia de Ferreira (2013, p. 201): "a essência da mudança do paradigma da avaliação está no acompanhamento do processo de ensino, contínuo, participativo, diagnóstico e investigativo, singular - no tempo adequado de aprendizagem de cada um". Entretanto, ainda para a autora, indo ao encontro dos diferentes posicionamentos manifestados, a mudança precisa ser assumida pelos professores, mas, para isso, é preciso que estes compreendam e acreditem na inversão defendida. McLaren (1977), ao discutir o processo de reprodução social como meio de perpetuar as relações dominantes, defende que os professores precisam desafiar os estudantes a serem auto-reflexivos, destacando que o processo de ensinar e aprender deveria ser um movimento de investigação e de crítica. Nesse sentido, ao encontro da perspectiva emancipatória de avaliação.

Assim, assumir a perspectiva emancipatória significa romper com o paradigma da avaliação classificatória e punitiva que condiciona a busca de notas no lugar do domínio do conhecimento. Significa oportunizar o protagonismo do estudante, desafiando-o a refletir não só sobre aspectos relacionados aos conteúdos, como, também, sobre seu contexto como um todo. Significa estabelecer o diálogo freireano, em que professor e aluno se reconhecem na incompletude que os constitui e assumem a luta pelas possibilidades concretas de compreensão e superação da realidade. Para Freire (1997, p. 64) "a consciência do mundo e a consciência de si como ser inacabado necessariamente inscrevem o ser consciente de sua inconclusão num permanente movimento de busca".

\section{Conceito e Nota: o Qualitativo e o Quantitativo}

Uma questão que emerge na fala de um professor, diz respeito à alteração da nota por um conceito, e como isso tem sido entendido. Nesse sentido, para esse professor, nada mudou, e a avaliação continua sendo pensada em uma lógica quantitativa.

[....] querem que a gente não dê nota, mas não tem outra forma da gente avaliar. Conceito! Mas como que a gente chega nesse conceito? ...a gente tenta fazer uma porcentagem, mas a porcentagem também é número, [...] eu faço a avaliação em notas e na hora de passar pro boletim, aí coloco conceito (Professor MP).

A fala do professor coloca em discussão a dificuldade de entender a perspectiva qualitativa que subjaz ao uso do conceito como representação da avaliação. Parece não haver outra forma de pensar a avaliação que não seja através de uma nota, que pode vir codificada em percentagem, números inteiros ou decimais, mas nada que não seja quantificável. O conceito parece ser o cumprimento burocrático da norma instituída e que, portanto, na hora do registro formal, substitui os números, até então usados na expressão dos resultados da avaliação. A concepção desse professor não é estranha ou pouco comum. Ela representa o entendimento de muitos professores nos diversos níveis de ensino, da Educação Básica até a Educação Superior.

Hoffmann (2013) e Luis (2012), têm discutido e ajudado a refletir sobre aspectos qualitativos e quantitativos da avaliação. Hoffmann (2013) convida o leitor a revisitar a Lei de Diretrizes e Bases da Educação (LDB) 9394/1996, na qual os aspectos qualitativos devem prevalecer sobre os quantitativos e, nesse sentido, ressalta que é preciso atribuir maior importância às observações sobre o desempenho dos estudantes, diversificando as formas de registros e ressignificando as possibilidades de interpretações. As ideias de Luis (2012, p. 37), complementam o olhar de Hoffmann (2013), quando diz:

Assumir uma prática avaliativa que se proponha à análise qualitativa da aprendizagem do aluno e de toda a prática escolar significa muito mais do que abandonar algumas técnicas e instrumentos de avaliação e rever o sistema de notas e conceitos, pois implica redefinir, numa dimensão teóricoprática, pressupostos que irão nortear um fazer pedagógico significativo, em que o conhecimento não seja visto como algo a ser adquirido, nem como algo independente dos sujeitos, das relações entre eles, nem da relação que estes estabelecem com o próprio conhecimento e com a cultura .

Na expressão dessa autora, assumir uma avaliação qualitativa, extrapola os aspectos instrumentais abrangendo o processo de ensino aprendizagem como um todo, superando a cultura conteudista, que prioriza a reprodução dos conteúdos, vistos de modo dissociado do contexto em que se inserem.

O Coletivo de Autores (2009), ao tratar da Avaliação em uma perspectiva crítico-superadora, reflete sobre as implicações metodológicas e pedagógicas na emissão de conceitos, chamando a atenção para o 
fato de que o conceito sempre foi interpretado como a transformação de uma nota, número - expressão quantitativa -, em um conceito, letra - expressão qualitativa. Entretanto, para o coletivo, o conceito não deve ser entendido somente como tradução de uma nota, mas representar um processo que implica inúmeros determinantes envolvendo desempenhos, conhecimentos, habilidades e atitudes nas atividades escolares. Ou seja, nessa análise, se evidencia a reiterada confirmação de que a interpretação dada ao uso do conceito não acompanha o caráter pretendido pelas orientações pedagógicas que optam por seu uso, nos desafiando a aprofundar reflexões que nos ajudem a compreender melhor tal fenômeno.

A manifestação de outra colaboradora introduz um elemento que parece implicar nas decisões sobre os registros do processo avaliativo, ou seja, a visão da comunidade:

Acredito que a escola se organizou duma forma bem legal, os alunos aceitaram, mas a sociedade ainda não aceitou. As pessoas precisam do retorno de uma nota. Nós temos o CSA o CPA e o CRA ${ }^{4}$, muito bonitos só que nós fizemos uma escala de graduação para tentar contentar a sociedade [...] aí tu tem o CSA linha 1, CSA linha 2 para explicar as equivalências do 9 ao 10 ou 7 ao 8 (Professora TD).

A fala da professora indica que os pais e/ou responsáveis também parecem tributários da ideia de avaliação como medida ou mensuração, cuja representação só admite a forma numérica, quantitativa, para dimensionar a aprendizagem ou não, de seus filhos na escola. E nesse viés se insere a preocupação principal com resultados finais, ou seja, com a aprovação ou a reprovação. Nesse sentido, a cultura que naturaliza o foco no produto é realimentada sem considerar o processo, as condições prévias de cada sujeito e os condicionantes sociais que atravessam a realidade escolar. No entendimento de Luis (2012), é fundamental que a avaliação não seja considerada ponto de chegada, mas ponto de partida para novas construções na busca da aprendizagem.

Entendemos que a compreensão da lógica da avaliação da aprendizagem, enquanto processo, está presente nas concepções formativa, discutida inicialmente a partir de Perrenoud (1999), mediadora, cunhada por Hoffmann, (1993), e, emancipatória, proposta por Saul (1998), pretendendo ressaltar a ressignificação do processo avaliativo, não mais como

4 De acordo com a proposta os conceitos a serem atribuídos aos alunos seriam esses: CSA, Construção Satisfatória da Aprendizagem; CPA Construção Parcial da Aprendizagem e CRA, Construção Restrita da Aprendizagem. simples verificação de um produto, mas, elemento constituinte do processo de ensinar e aprender, visando dinamizar as aprendizagens e regular o ensino.

Portanto, a avaliação emancipatória, concepção assumida pela proposta do RS, cuja representação se expressa nos conceitos: CSA; CPA e CRA, é entendida pelos professores a partir das diversas manifestações que representam diferentes modos e percepções de encaminhamento didático-pedagógico.

\section{A Questão da Prova}

Indo ao encontro do sentido dado à perspectiva avaliativa emancipatória, um dos colaboradores desta pesquisa explica o que entende por avaliação emancipatória:

Eu acredito que isso seja um processo contínuo, mas, nem todo mundo tem facilidade de trabalhar dessa forma. Então, por exemplo: a avaliação emancipatória deve ser feita continuamente, mas ainda há provas, e ainda há trabalhos. Então o aluno percebe que o trabalho em sala de aula, a construção contínua, não é tão importante quanto fazer uma prova ou um trabalho. Essa avaliação da prova ainda não foi abolida, e eu acredito numa avaliação emancipatória que seja num sentido de que a construção do processo seja todos os dias, não seja só na prova. E eu acho que deveria ser abolida. Mas não é fácil para o professor. Como não vou mais ter prova? Então vou aprovar todo mundo? Como é que é isso? Então esbarra não só nos professores mais antigos, mas esbarra em todo mundo. Porque a nossa formação não foi emancipatória, a nossa formação foi tradicional (Professor MD).

Há muitas questões a serem analisadas na fala desse professor. Inicialmente, ele destaca o caráter processual e contínuo, colocando em confronto tal aspecto com a realização de provas e de trabalhos avaliativos. Nesse sentido, manifesta sua posição contrária à realização de provas, ao mesmo tempo em que admite não ser fácil trabalhar sem o uso desse instrumento. Apresenta, ainda, a visão dos seus colegas sobre a soberania da prova como única forma de verificação eficiente do aproveitamento dos estudantes e, consequentemente, legitimadora de qualquer possibilidade de reprovação. E, por fim, sugere que as dificuldades vivenciadas para a efetiva mudança na prática pedagógica da avaliação estão na formação inicial dos professores que, independente do tempo de formação, não mudou, não avançou, continuando pautada em uma visão tradicional.

A respeito dos instrumentos avaliativos, ao falar sobre o uso de provas, sugere que as provas acabam monopolizando o processo avaliativo. É uma questão 
interessante a ser debatida, considerando-se as possibilidades de buscar outras alternativas de proceder a avaliação, procurando romper com o uso hegemônico da prova, no processo avaliativo. Do mesmo modo, há, nas entrelinhas da fala do professor, uma aparente relação entre prova e avaliação tradicional, visão que tem se perpetuado por conta do significado atribuído à prova na prática pedagógica em que a avaliação se resume à aplicação de provas ao final de um período letivo, consubstanciando-se uma lógica, autoritária, sentensiva e terminal (HOFFMAN, 1991).

Sobre a construção do processo avaliativo ao longo dos dias, como comenta o professor, tal enunciação sugere uma avaliação enquanto acompanhamento, nos diferentes momentos e situações em que o conhecimento esteja colocado como objeto a ser apropriado pelos alunos. Nas palavras de Luis (2012, p. 38), consubstancia-se, então, a chamada avaliação informal:

Nesse sentido, precisamos reconhecer que nosso trabalho pedagógico apresenta práticas avaliativas cotidianas que estão permeadas de múltiplos aspectos, em função da própria complexidade do ensinar e aprender, as quais constituem o que se costuma chamar de avaliação informal. Essa avaliação informal, superando o temor pela subjetividade, precisa ser mais valorizada, tornandose seus critérios cada vez mais claros e as práticas de observação mais sistemáticas e abrangentes, a fim de que se constituam com fontes legítimas de decisões para nós, professores, e de reflexão para nossos alunos.

Tal processo, denominado por Luis de avaliação informal, precisa de alguma forma de registro, com a perspectiva de poder ser sistematizado como instrumento para leitura e interpretação da realidade vivenciada; precisa se transformar em informação, em elemento que ajude a traduzir o processo de aprendizagem de cada aluno, da turma, e a validade das estratégias de ensino.

\section{CONCLUSÕES}

Inicialmente, destacamos que a realização deste estudo reestabeleceu laços com a educação de Quaraí, permitindo que revisitássemos aspectos socioeconômicos e culturais que historicamente marcam a trajetória educacional da juventude local.

$\mathrm{Em}$ relação ao objetivo de compreender de que modo os professores de Educação Física percebem e praticam a avaliação, a partir da perspectiva emancipatória presente nas orientações curriculares, foi possível vislumbrar que:
- Há diferentes percepções sobre a concepção avaliativa emancipatória que transitam entre os colaboradores do estudo, evidenciando que o processo está instalado e tem problematizado a prática docente, podendo ser um potencializador de movimentos de formação continuada e de novas trocas na comunidade escolar;

Emerge, das informações colhidas, o tensionamento entre nota e conceito, trazendo para o centro da discussão as perspectivas qualitativa e quantitativa de avaliação, que se encontram subjacentes ao entendimento necessário para superar a simples substituição de uma pela outra mediante parâmetros quantitativos;

- A questão da prova surge a partir do questionamento sobre certa soberania atribuída a essa estratégia didática, ao mesmo tempo, parecendo relacioná-la a modelos tradicionais de educação, mas colocando em discussão outras possibilidades de diversificação de instrumentos e momentos avaliativos, o que concorre para a discussão sobre as funções da avaliação e sua importância enquanto parte do processo de construção de conhecimento.

A par das discussões aqui apresentadas, o olhar atento sobre o que está sendo proposto em nome do melhor direcionamento para o Ensino Médio, em tempos de acirramento de políticas neoliberais, constitui-se em compromisso político de educadores e pesquisadores preocupados com a escola pública democrática e de qualidade. Nesse sentido, se constitui em um posicionamento de resistência, a problematização dos processos de formação continuada e de leitura crítica da atual conjuntura, tendo em vista o fortalecimento da Educação Física como componente curricular do EM e a consolidação deste, como efetiva etapa final da Educação Básica.

\section{REFERÊNCIAS}

BOGDAN, R. e BIKLEN, S. (1994). Investigação Qualitativa em educação: uma introdução à teoria dos métodos. Porto: Porto.

BRASIL. (1996). Ministério da Educação. Lei no 9.394 de 20 de dezembro de 1996. Lei de Diretrizes e Bases da Educação Nacional. Recuperado de http://www.planalto.gov.br/ ccivil_03/leis/19394.htm.

BRASIL. (2012). CNE. Resolução nํ2 de 2012. Diretrizes Curriculares Nacionais para o Ensino Médio. Recuperado de http://portal.mec.gov.br/index.php?option=com_ docman\&view =download \&alias $=9864-$ rceb00212\&category_slug=janeiro-2012-pdf\&Itemid=30192.

COLETIVO DE AUTORES. (2009). Metodologia do ensino da Educação Física. São Paulo: Cortez.

FERREIRA, V. M. (2013). Ensino Médio Politécnico: mudança de paradigma. In AZEVEDO, J. C. e REIS, J. Reestruturação Curricular do Ensino Médio. São Paulo: Fundação Santillana. 
FREIRE, P. (1997). Pedagogia da autonomia: saberes necessários à prática educativa. São Paulo: Paz e Terra.

HOFFMANN, J. (1991). Avaliação mito e desafio. Porto Alegre: Mediação.

HOFFMANN, J. (1993). Avaliação Mediadora: uma prática em construção da pré-escola à universidade. Porto Alegre: Mediação.

HOFFMANN, J. (1998). Pontos e contrapontos: do pensar ao agir em avaliação. Porto Alegre: Mediação.

HOFFMANN, J. (2013). Avaliar: respeitar primeiro educar depois. Porto Alegre: Mediação, 2013.

LUIS, S. M. B. (2012). De que avaliação precisamos em arte e educação física? In: SILVA, Janssen Felipe da; HOFFMANN, J.; ESTEBAN, M. R. (Org.). Práticas avaliativas e aprendizagens significativas: em diferentes áreas do currículo. Porto Alegre: Mediação.

MCLAREN. Peter. (1977). A vida nas escolas. Porto Alegre: Artes médicas.
MARTINS, C. (1997). Sem rumo. Porto Alegre: Movimento.

MOLINA, R. M. K. (2010). O enfoque teórico metodológico qualitativo e o estudo de caso: uma reflexão introdutória. In MOLINA NETO, V. e TRIVIÑOS, A. A pesquisa qualitativa na Educação Física: alternativas metodológicas. Porto Alegre: Sulina.

PERRENOUD, P. (1999). Avaliação: da excelência à regulação das aprendizagens. Porto Alegre: ArtMed.

RIO GRANDE DO SUL. (2011-2014). SEDUC. Proposta pedagógica para o Ensino Médio politécnico e educação profissional integrada ao Ensino Médio. Recuperado de http://servicos. educacao.rs.gov.br/dados/ens_med_proposta.pdf.

SILVA, J. L. C.; SILVEIRA, E. da S. Avaliação emancipatória do ensino médio politécnico: experiências etnográficas na Educação Física. Estudos em Avaliação Educacional (2018), v. 29, n. 71 , p. $472-503$.

SAUL, A. M. (1998). Avaliação Emancipatória. São Paulo: Cortez. 